\title{
Epidemiological Composition, Clinical and Treatment Characteristics of the Patient Cohort of the German COMPETENCE NETWORK FOR HIV/AIDS
}

\author{
K. Jansen ${ }^{1}$, N. H. Brockmeyer ${ }^{1,2}$, M. Hahn³, I. Kaul ${ }^{3}$, S. Fenske ${ }^{4}$, M. Rausch ${ }^{5}$, B. Kuhlmannn, \\ A. Ulmer ${ }^{7}$, E. Lauenroth-Mai ${ }^{8}$, T. Harrer ${ }^{9}$, M. Hower ${ }^{10}$, A. Skaletz-Rorowski ${ }^{1}$, C. Michalik ${ }^{11}$, \\ and the Competence Network for HIV/AIDS
}

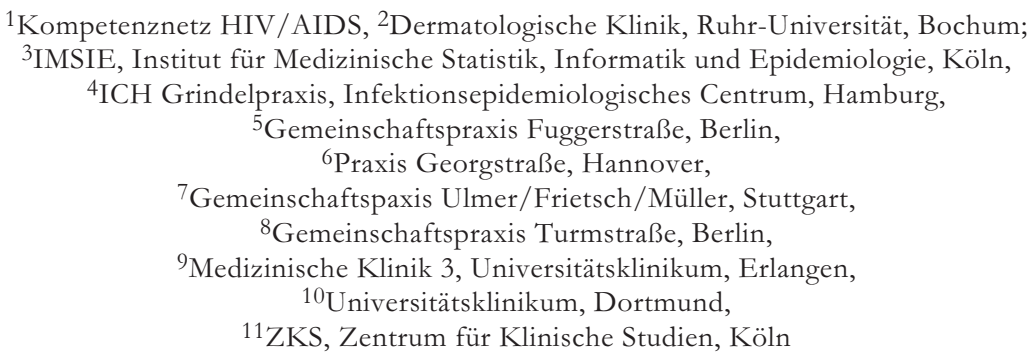

\section{Abstract}

Objective: As its central basis for research, the Competence Network for HIV/AIDS (KompNet) established a nationwide cohort study on HIV-positive patients being in medical care in Germany. In this paper, we describe the epidemiological composition, and clinical as well as treatment characteristics of the KompNet cohort over time.

Methods: The KompNet cohort is an open, retrospective and prospective, multi-center, disease-specific and nationwide cohort study that started gathering data in June 2004. Semiannually, follow up visits of the patients are documented, covering a wide range of clinical and sociodemographic data. At enrolment and three years afterwards, an EDTA-sample is taken; a serum-sample is taken at every follow up.

Results: As of 20.10.2008, a total of 15,541 patients were enrolled by 44 documenting sites. In September 2007, the cohort size was reduced to ten outpatient clinics and fifteen private practitioners, covering a total of 9,410 patients. The documentation of these patients comprised 24,117 years of follow up-time since enrolment (mean: 2.6 years), 62,862 person years inclusive data documented retrospectively on course of HIV-infection and antiretroviral therapy (ART, mean: 6.7 years). Due to the short period of recruitment till now, rates of death $(0.3 \%-0.8 \%)$ and losses to follow up $(1.1 \%-5.5 \%)$ were low.

$84.9 \%$ of patients were men. Main risk of transmission was sex between men (MSM: 62.9\%). Mean age was 45 years. About two third of patients were classified as CDC-stage B or C. Therapy regimens of currently treated patients complied with recent guidelines. Trends of mean CD4 cell count/ $\mu$ l regarding the initial therapy and concerning the population under treatment reflected the developments and the changing standards of antiretroviral therapy over time.
Conclusion: The KompNet cohort covers about a quarter of all patients estimated as being under treatment in Germany. Its composition can be accounted approximately representative for the situation of clinical care and treatment in the scope of HIV/AIDS in Germany. Therefore, it is an important instrument for measuring the course of HIV/AIDS, the reality of use of antiretroviral therapy and its clinical and psychosocial outcomes in Germany.

Key words: Cohort Study, HIV/AIDS, Germany, Epidemiology, Clinical Research, Profile, Competence Network HIV/AIDS

\section{INTRODUCTION}

In 2004, the German Competence Network for HIV/AIDS (KompNet) started enrolment of patients for its nationwide cohort study on HIV-positive patients [1]. KompNet is a national scientific network with focus on HIV/AIDS that is funded by the Federal Ministry of Education and Research. In the field of HIV/AIDS, it brings together researchers of basic and clinical science, social sciences and public health as well as research with special regard to children and gender, and aims at transferring its scientific results into clinical practice.

The KompNet cohort study was established as the central basis for research within the network, but also to support scientific collaborations with researchers from outside the KompNet. By collecting a wide range of clinical and sociodemographic data as well as biomaterials on a regular basis [1], the main objectives of the KompNet cohort study are (1) to monitor the epidemiological composition of HIV-positive patients, as representatively as possible for the German situation, (2) to monitor the course of HIV-infection and the ef- 
fects of cART, its side effects, concomitant diseases and their treatment and to analyse underlying mechanisms on national level, and (3) to provide clinical data as well as biomaterials to scientific projects from inand outside the KompNet and to collaborate with similar scientific projects, on national and international level.

At the end of 2008, 63,500 persons infected with HIV lived in Germany, thereof 10,500 persons with AIDS [2]. In 2008, 2,806 newly diagnosed HIV infections were reported to the Robert Koch-Institute [3]. This number grew constantly between 2001 and 2008 from 1,443 to 2,806 per year, with a flattening since 2006. The epidemiology of HIV/AIDS in Germany is characterised by a high proportion of men. Sex between men (MSM) is the main risk of transmission. MSM was risk of transmission in 65\% of all reported newly diagnosed HIV-infections in 2008, followed by heterosexual contacts $(17 \%)$ and persons originating from high prevalence countries $(12 \%)$ [3]. Compared to that, intravenous drug use was of minor importance in Germany (5\%). New infections are diagnosed predominantly in urban areas. Reported AIDS cases declined from about 2,000 in 1995 to about 550 in 2007 , but a high number of unreported cases is presumed [3]. The number of AIDS cases in 2008 is estimated as about 1,100. This high number is supposed to be caused by late testing and a late start of cART.

Following the prior use of antiretroviral therapy (ART), the distinct more effective combined antiretroviral therapy (cART) was introduced in Germany 1996. After introduction of cART, the number of reported AIDS cases and deaths due to AIDS in Germany decreased heavily, in coincidence with an increasing HIV prevalence due to increased life expectancy [3]. The current number of patients treated with (cART) in Germany is estimated as 30,000 [4]. cART of HIV/AIDS improved distinctly within the last years, especially in Western countries. Not only many new and potent drugs of well known substance classes as protease inhibitors (PI), nucleoside reverse transcriptase inhibitors (NRTI) and non-nucleoside reverse transcriptase inhibitors (NNRTI) were introduced, which built the basis for cART since 1996. Also complete new substance classes were developed and mostly brought into standard medical practice, such as fusion inhibitors, integrase inhibitors, co-receptor antagonists and maturation inhibitors. Therewith, therapy of HIV/AIDS and its effects become complex more than ever, affecting the clinical as well as the psychosocial situation of the patients.

On basis of the KompNet cohort, it is possible to study this high complexity of HIV/AIDS therapy in Germany in its details. In this article, we present central epidemiological, clinical and treatment characteristics of the KompNet cohort.

\section{Methods}

The KompNet cohort is an open, retrospective and prospective, multi-center, disease-specific and nationwide cohort. It started enrolment patients in 2004. The data come from and are documented by 25 sites all over Germany.
For a detailed description as to the composition of the cohort, recruitment procedures, documentation of prospective and retrospective data and other methodological issues, please see [1].

If available at the documenting site, retrospective data of patients are documented, containing data of the period before enrolment of the patient into the cohort. The retrospective documentation of data comprises the therapy status, prescribed antiretroviral treatment, CDC-stage, CD4 cell count/ $\mu \mathrm{l}$, viral load. For analysing the course of treatment, it is essential to know the time point till which the patient was therapynaïve. Otherwise, analyses on the course and effects of ART can be biased by a former, undocumented ART. Therefore, the cohort documentation contains a variable indicating whether the patient was assured therapy-naïve at first documentation of data or not. By now, therapy status at start of medical care at the currently documenting site is not known for a subgroup of patients, e.g. because this patients were treated in another institution before attending the current documenting site. Missing data on therapy status at first documentation in the cohort is under ongoing evaluation in collaboration with the documenting sites. For all analyses referring to the time point of initial therapy, only patients with assured documented ARTnaivety were eligible.

Student's t-test and $\chi^{2}$-tests were used to compare groups.

State of date for all analyses was 20.10.2008.

\section{RESULTS}

\section{DESCRIPTION OF RECRUITMENT}

Enrolment of the first patient took place in April 2004. The cohort covers a total of 15,541 patients, reported by 44 documenting sites over time. After a process of reduction in 2007, the KompNet cohort consists of 25 documenting sites currently [1], covering a total of 9,410 patients. Of these, 8,223 patients were reported as having an ongoing documentation since inclusion into cohort till state of date 20.10.2008. ${ }^{1}$ The number of newly recruited patients decreased due to a recruitment stop in 2008 (Table 1). The number of documented patients (including retrospective data) increased over the years till 2006 (Fig. $1)$. The number of patients documented prospectively increased till 2007 (Table 1).

The proportion of patients having retrospective documentation of data was $89.8 \%$, independently from the covered period of retrospective documentation. The population of 9,410 patients of the currently documenting sites contributed 24,117 person-years prospectively (mean: 2.6 years). 62,862 person-years were documented including retrospective data (mean: 6.7 years), thereof 6,995 person-years of treatmentnaive periods and 55,867 person-years under cART, the latter including 3,776 person-years of treatment interruptions.

\footnotetext{
${ }^{1}$ Compared to numbers reported in [1], the number of patients reported as actively under follow-up was reduced by four patients due to lost to follow-up.
} 


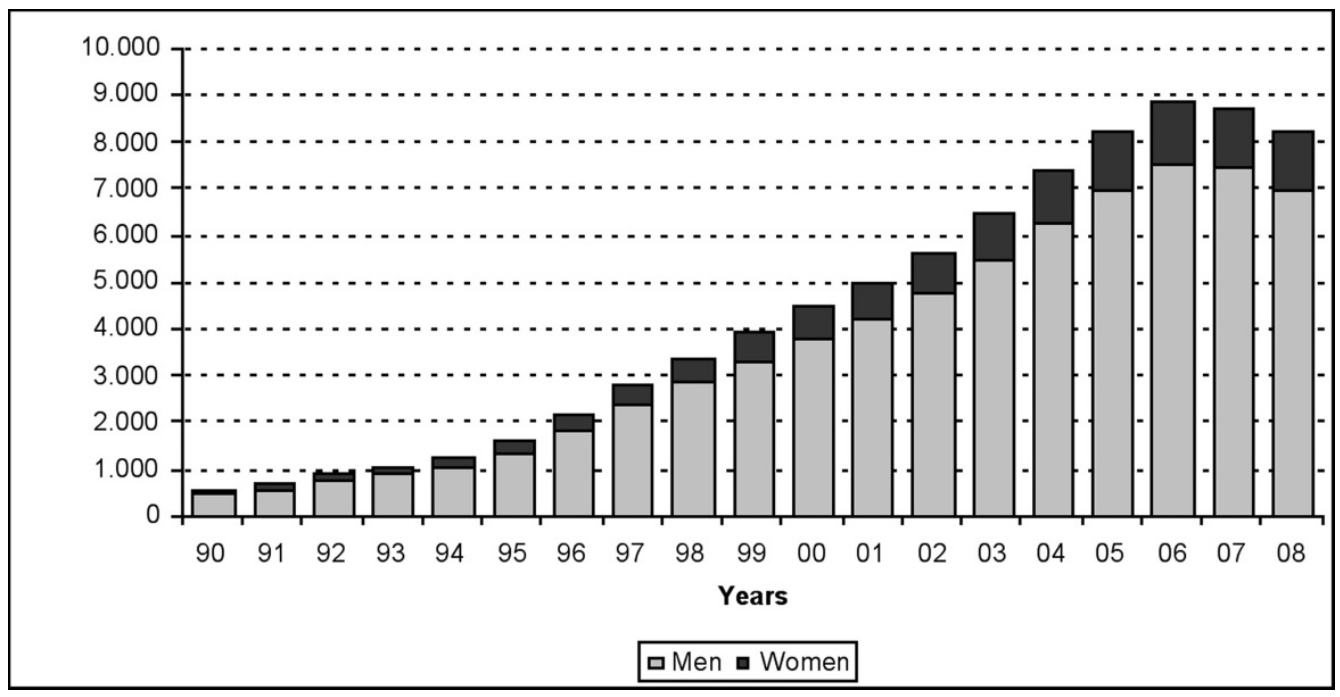

Fig. 1. Number of documented patients, distribution of sex, including retrospective data, 1990-2008, by year $(\mathbf{N}=9,410)$.

Table 1. Recruitment and sociodemographic characteristics of patients being under follow-up at the respective year since enrolment, 2004-2008, by year $(\mathrm{N}=9,410)$.

\begin{tabular}{|c|c|c|c|c|c|}
\hline & & & Year & & \\
\hline & 2004 & 2005 & 2006 & 2007 & 2008 \\
\hline No. of newly recruited patients ${ }^{1}$ & 1,991 & 3,966 & 2,531 & 876 & 46 \\
\hline Proportion of men $(\%)$ & 84.5 & 85.4 & 85.6 & 83.3 & 91.3 \\
\hline Mean duration since first positive HIV- & 8.0 & 8,2 & 7,2 & 5,5 & 4,4 \\
\hline diagnosis to enrolment (years, IQR) & $(3.1-12.0)$ & $(2.9-12.4)$ & $(1.9-10.9)$ & $(0.5-9.0)$ & $(0.5-7.6)$ \\
\hline No. of patients followed up prospectively & 1,991 & 5,952 & 8,395 & 8,886 & 8,367 \\
\hline Proportion of men $(\%)$ & 84.5 & 85.1 & 85.2 & 85.1 & 84.8 \\
\hline Proportion of deaths $(\%)$ & 0 & 0.3 & 0.7 & 0.8 & 0.3 \\
\hline Proportion of losses to follow up (\%) & 0 & 1.1 & 3.8 & 5.5 & 1.4 \\
\hline Proportion of patients treated at & & & & & \\
\hline Clinics $(\%)$ & 58.9 & 33.4 & 26.7 & 26.6 & 26.5 \\
\hline Private practices $(\%)$ & 41.1 & 66.6 & 73.3 & 73.4 & 73.5 \\
\hline Mean age at enrolment & & & & & \\
\hline Men (years, IQR) ${ }^{2}$ & 45.2 & 43.8 & 42.3 & 41.3 & 43.5 \\
\hline & $(37.6-51.6)$ & $(37.2-49.1)$ & $(36.5-47.5)$ & $(34.9-46.3)$ & $(38.4-48.3)$ \\
\hline Women (years, IQR) & 41.4 & 40.0 & 39.5 & 39.2 & 31.6 \\
\hline & $(33.5-46.9)$ & $(32.8-44.6)$ & $(32.7-44.5)$ & $(31.9-45.9)$ & $(21.5-41.7)$ \\
\hline Vocational situation of male patients & & & & & \\
\hline Fully employed (> 34 h/week) & 18.3 & 38.3 & 40.6 & 41.4 & 42.8 \\
\hline Part time work (15-34 h/week) & 0.5 & 4.2 & 5.0 & 5.4 & 5.3 \\
\hline Work by the hour (<15 h/week) & 0.3 & 2.4 & 2.6 & 2.7 & 2.8 \\
\hline Not employed & 10.8 & 33.9 & 33.5 & 32.2 & 31.3 \\
\hline Other & 0.9 & 1.1 & 1.0 & 1.0 & 1.7 \\
\hline Not known & 69.2 & 20.1 & 17.3 & 17.3 & 16.1 \\
\hline Vocational situation of female patients & & & & & \\
\hline Fully employed (> 34 h/week) & 9.1 & 17.9 & 18.7 & 20.3 & 21.0 \\
\hline Part time work (15-34 h/week) & 2.0 & 11.3 & 12.9 & 13.1 & 13.9 \\
\hline Work by the hour (<15 h/week) & 0 & 3.9 & 4.6 & 4.3 & 4.9 \\
\hline Not employed & 14.1 & 45.4 & 43.2 & 43.7 & 42.4 \\
\hline Other & 1.0 & 2.1 & 1.9 & 1.2 & 1.8 \\
\hline Not known & 73.8 & 19.4 & 18.7 & 17.4 & 16.0 \\
\hline
\end{tabular}

${ }^{1}$ Low number of newly recruited patients in 2008 due to a recruitment stop in 2008.

2IQR: Inter Quartile Range (25\%-75\%). 
Over time, 1,012 losses to follow up (10.8\%) and 175 deaths $(1.9 \%)$ were registered. $55.6 \%$ of all losses to follow up were due to a known change to another treating institution not participating in the KompNet cohort. Death- and lost to follow up-rates increased over the years (Table 1). The mean duration since the first positive HIV-diagnosis to enrolment into the cohort decreased strongly over time Table 1).

\section{SOCIODEMOGRAPHIC CHARACTERISTICS}

$84.9 \%$ of the enrolled patients were men; the sex distribution stayed stable over the years regarding the patient population with documented retrospective data (Fig. 1), the population of newly recruited patients as well as the population of patients followed up prospectively (Table 1). The proportion of women fluctuated between about $15 \%$ and $17 \%$ regarding these three populations.

The mean age at enrolment fluctuated between 41 to 45 years $^{2}$ in men and 39 to 41 years in women (with exception of 2008 with very few newly recruited women, Table 1). The mean age differed between men

${ }^{2}$ Reference date for calculation of age: August 1st.
(46, IQR: 40-52) and women (43, IQR: 36-48), $\mathrm{p}<0.001)$. The distribution of age groups changed over the years towards groups of higher age (Fig. 2). The proportion of patients being older than 49 years in 2008 was $28.1 \%$.

Main risk of transmission was sex between men (MSM) (Fig. 3). The proportion of intravenous drug users (IVDU) decreased over time, the proportion of patients coming from high prevalence countries (HPL) as well as patients infected by heterosexual contacts increased.

Most frequent country of origin of patients was Germany with a proportion between $81.9 \%$ and $86.4 \%$ and a light decrease over the years; proportions of patients originating from Central/Eastern European states $(3.1 \%$ to $4.0 \%)$ as well as Sub-Saharan countries $(2.6 \%$ to $4.7 \%)$ increased lightly (Fig. 4). There were distinct differences regarding the migration background (country of origin other than Germany) between men and women: $14.4 \%$ of men, but $38.2 \%$ of women $(p<0.001)$ were migrated, with special emphasis of Subsaharan and Asian countries in women [1]. The federal states of Bavaria, Berlin, Northrhine-Westfalia, and Hamburg covered $85.8 \%$ of all patients with ongoing documentation (Table 2).
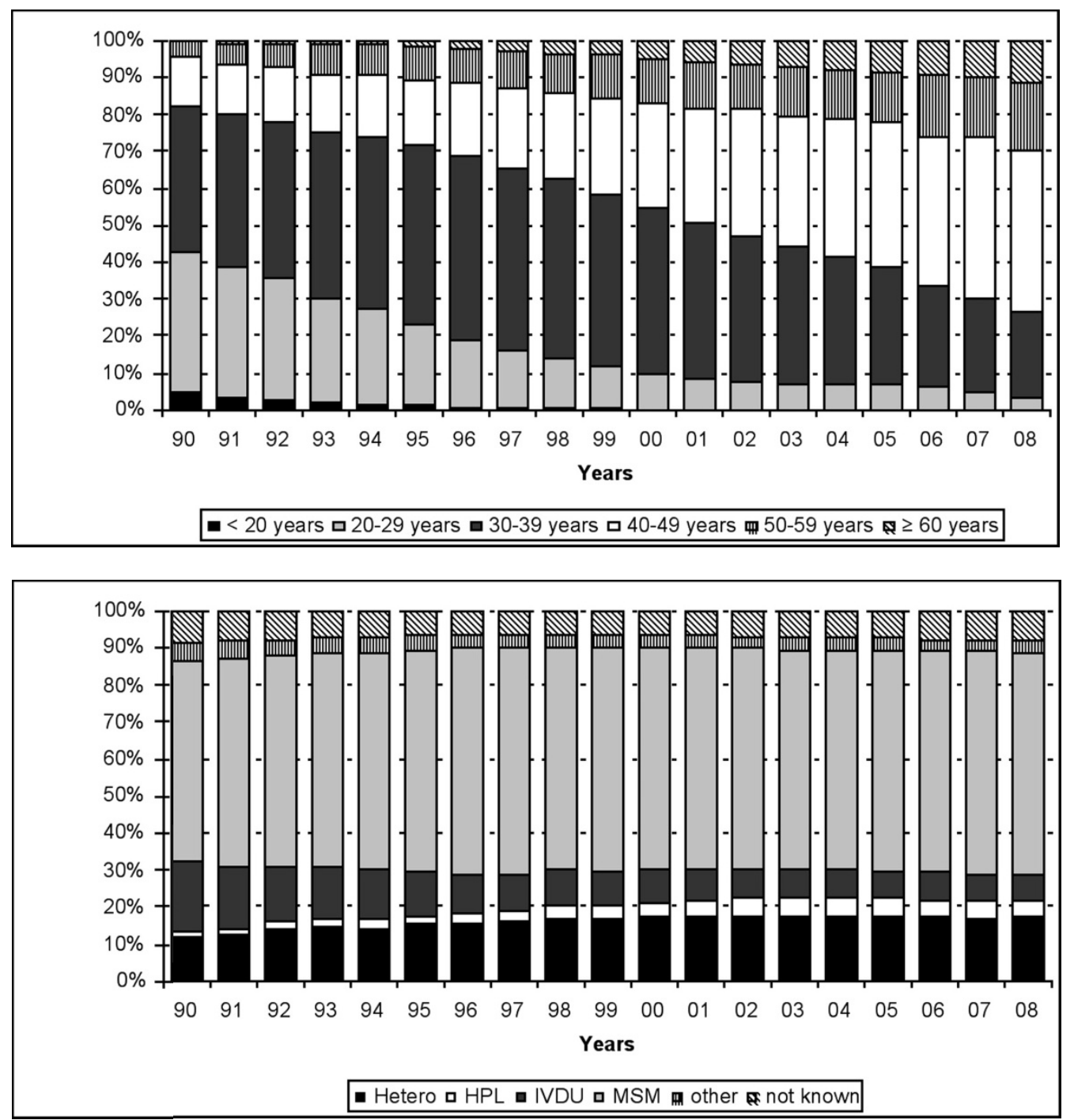

Fig. 2. Distribution of age groups, including retrospective data, 1990-2008, by year $(\mathrm{N}=9,410)$.
Fig. 3. Distribution of risk of transmission, including retrospective data, 19902008 , by year $(\mathrm{N}=$ $9,410)$. 


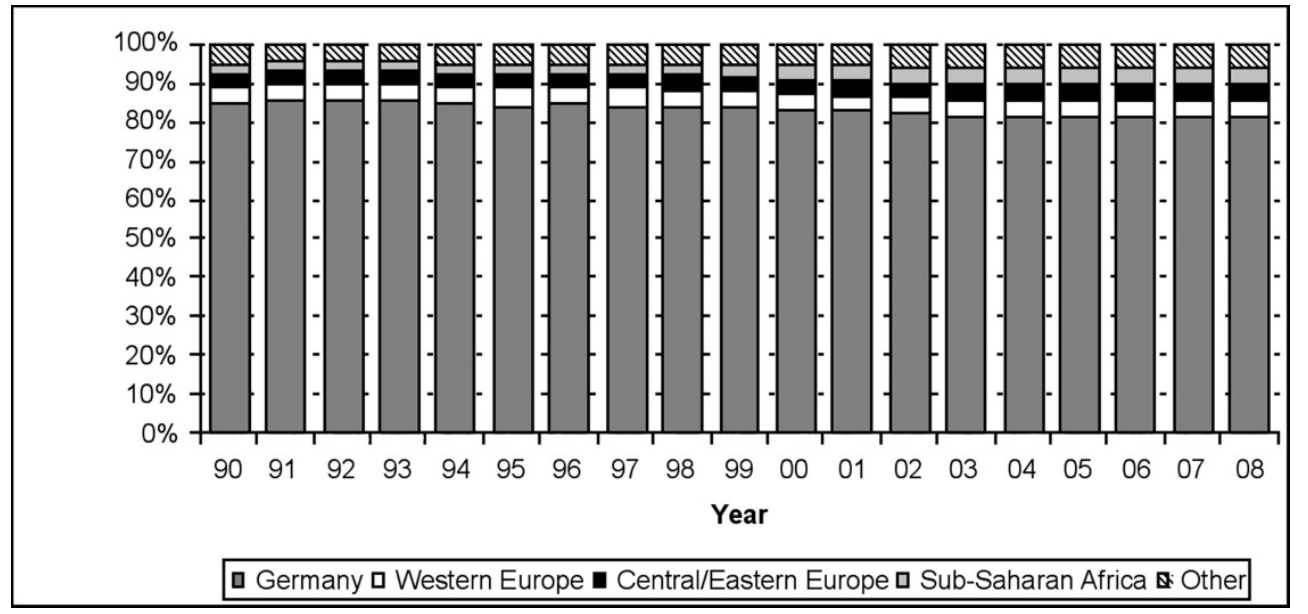

Fig. 4. Distribution of country of origin, including retrospective data, 1990-2008, by year $(\mathrm{N}=$ $9,410)$.

Table 2. Geographical distribution of the KompNet cohort, all patients and patients under follow up at 20.10.2008.

\begin{tabular}{lcc}
\hline Federal State & \multicolumn{2}{c}{$\begin{array}{c}\text { Number of patients } \mathbf{( \% )} \\
\text { Patients under follow-up }\end{array}$} \\
\hline Baden-Wurttemberg & $354(3.8)$ & $342(4.1)$ \\
Bavaria & $1,729(18.4)$ & $1,572(19.1)$ \\
Berlin & $2,985(31.7)$ & $2,460(29.9)$ \\
Hamburg & $1,567(16.7)$ & $1,449(17.6)$ \\
Hesse & $134(1.4)$ & $95(1.1)$ \\
Northrhine-Westfalia & $1,801(19.1)$ & $4,564(19.2)$ \\
Lower Saxony & $754(8.0)$ & $660(8.0)$ \\
Rhineland-Palatinate & $86(0.9)$ & $81(1.0)$ \\
\hline Total & $9,410(100.0)$ & $8,223(100.0)$ \\
\hline
\end{tabular}

There were strong and timely stable differences between sexes regarding the vocational situation (Table 1). About double as much men as women were fully employed. About a third of men and more than 40\% of women were unemployed over the years (with exception of 2004 with a high proportion of missing data on vocational situation).

\section{Clinical Data and Antiretroviral Therapy}

With exception of 2004, the proportion of patients treated by specialised private practitioners was between $67 \%$ and $74 \%$ (Table 1 ).
Stable over time, nearly half of all patients were classified as CDC-stage B, about a quarter as CDCstages A or C, each (Fig. 5). Regarding the risk of transmission, IVDU had the lowest proportion $(21.1 \%)$ of patients classified as CDC-stage A (Table 3). With 40.7\%, patients originating from HPL were classified distinct more frequent as CDC-stage A than patients having another risk of transmission. The mean age at HIV-diagnosis was lower in women (32, IQR: 25-37) as in men (36, IQR: 29-41, p $<0.001)$.

Prevalence of Hepatitis B coinfection varied between $1.6 \%$ in IVDU $(6.3 \%$ Hepatitis B/C coinfec-

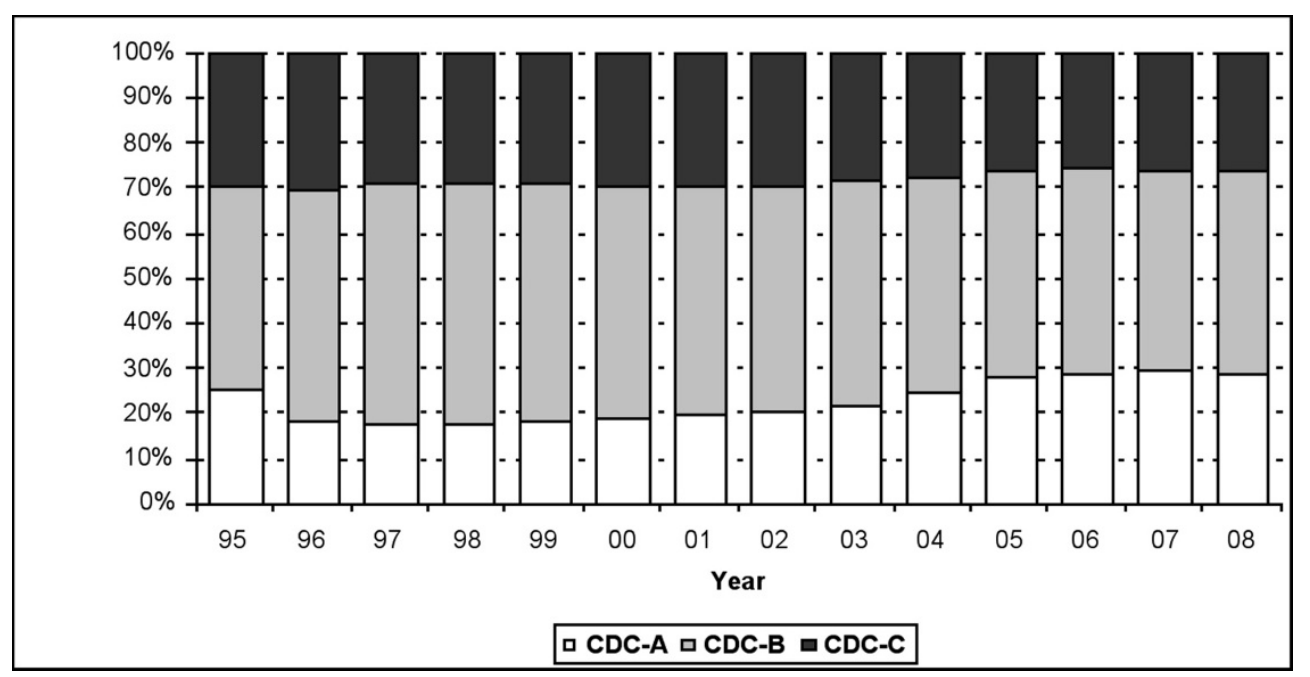

Fig. 5. Distribution of CDC-stage, including retrospective data, 19952008 , by year $(\mathrm{N}=$ $9,410)$. 
Table 3. Baseline clinical and treatment characteristics of patients under follow-up at 20.10.2008, by risk of transmission $(\mathrm{N}=8,213)$.

\begin{tabular}{|c|c|c|c|c|}
\hline & \multicolumn{4}{|c|}{ Risk of transmission } \\
\hline & Hetero & HPL & IVDU & MSM \\
\hline Proportions of risk of transmission $(\%)^{1}$ & 18.4 & 5.2 & 7.0 & 63.0 \\
\hline \multicolumn{5}{|l|}{ Current CDC-stage $(\%)$} \\
\hline A & 31.1 & 40.7 & 23.1 & 28.2 \\
\hline $\mathrm{B}$ & 43.4 & 33.4 & 51.1 & 46.4 \\
\hline $\mathrm{C}$ & 25.5 & 25.9 & 25.8 & 25.4 \\
\hline \multicolumn{5}{|l|}{ Prevalence of Hepatitis-Co-Infections $(\%, \mathrm{~N}=6,279)^{2}$} \\
\hline Hepatitis B & 3.4 & 7.3 & 1.6 & 5.5 \\
\hline Hepatitis C & 11.4 & 4.5 & 71.2 & 6.5 \\
\hline Hepatits B + C & 1.0 & 0.3 & 6.3 & 0.7 \\
\hline \multirow[t]{2}{*}{ Mean CD4 cell count/ $\mu \mathrm{l}$ at date of first documentation (IQR) } & 327 & 298 & 370 & 387 \\
\hline & $(123-479)$ & $(109-400)$ & $(170-500)$ & $(179-536)$ \\
\hline \multirow[t]{2}{*}{ Mean CD4 cell count/ $\mu$ l of currently treated patients (IQR) } & 533 & 490 & 480 & 553 \\
\hline & $(331-670)$ & $(334-630)$ & $(266-591)$ & $(362-698)$ \\
\hline \multirow[t]{2}{*}{$\begin{array}{l}\text { Number of treated patients documented as assured therapy- } \\
\text { naïve at start of documentation }(\mathrm{N}=3,230 ; \%)^{3}\end{array}$} & 655 & 222 & 213 & 2140 \\
\hline & $(20.3)$ & $(6.9)$ & $(6.6)$ & $(66.2)$ \\
\hline \multirow[t]{2}{*}{ Mean CD4 cell count/ $\mu$ lat start of initial ART, (IQR) } & 288 & 258 & 319 & 301 \\
\hline & $(138-403)$ & $(110-375)$ & $(170-420)$ & $(170-394)$ \\
\hline \multirow[t]{2}{*}{ Mean HIV RNA at start of initial ART, mean log copies/ml (IQR) } & 4.0 & 4.1 & 3.8 & 4.3 \\
\hline & $(3.0-5.1)$ & $(3.2-5.1)$ & $(2.7-5.0)$ & $(3.5-5.2)$ \\
\hline $\begin{array}{l}\text { Proportion of patients having CD } 4 \text { cell count } / \mu \mathrm{l}<150 \text { at start of } \\
\text { initial ART }(\%)\end{array}$ & 26.0 & 33.6 & 20.6 & 20.5 \\
\hline
\end{tabular}

${ }^{1}$ Other risks of transmission low frequent and not showed, multiple answers possible.

${ }^{2} \mathrm{~N}$ reduced to 6,279; for 1,944 patients no data on tests for Hepatitis B/C available; prevalences including acute and chronic Hepatitis as well as state after Hepatitis B/C (tested serologically).

${ }^{3}$ Only patients being documented as assured therapy-naïe at start of documentation were eligible for analyses regarding start of initial ART.

tion, additionally) and $7.3 \%$ in HPL (Table 3); prevalence of Hepatitis C coinfection varied heavily between $4.5 \%$ in HPL and $71.2 \%$ in IVDU.

Of 4,944 patients, the therapy status (therapy-naïve or not) at start of documentation was given. $83.1 \%$ were therapy-naïve at start of documentation, so the complete cART-history of this subpopulation could be documented. The proportion of patients under treat- ment increased over time; the proportion of patients having a treatment interruption increased, also (Fig. 6) ${ }^{3}$.

\footnotetext{
${ }^{3}$ Patients that were under treatment and had a treatment interruption in the same year were numbered among patients having a treatment interruption; patients that were naïve and started a treatment were numbered among treated patients regarding the year of their initial therapy.
}

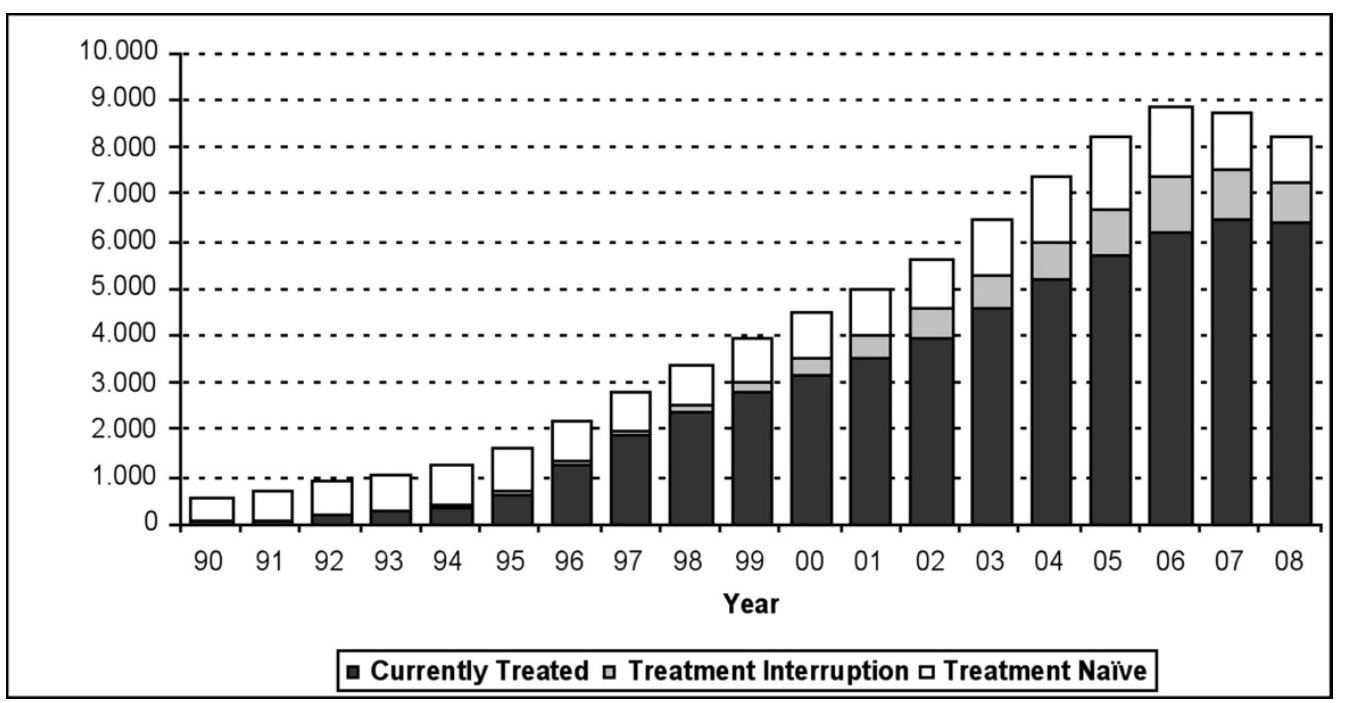

Fig. 6. Therapy status including retrospective data, 1990-2008, by year $(\mathrm{N}=9,410)^{3}$. 


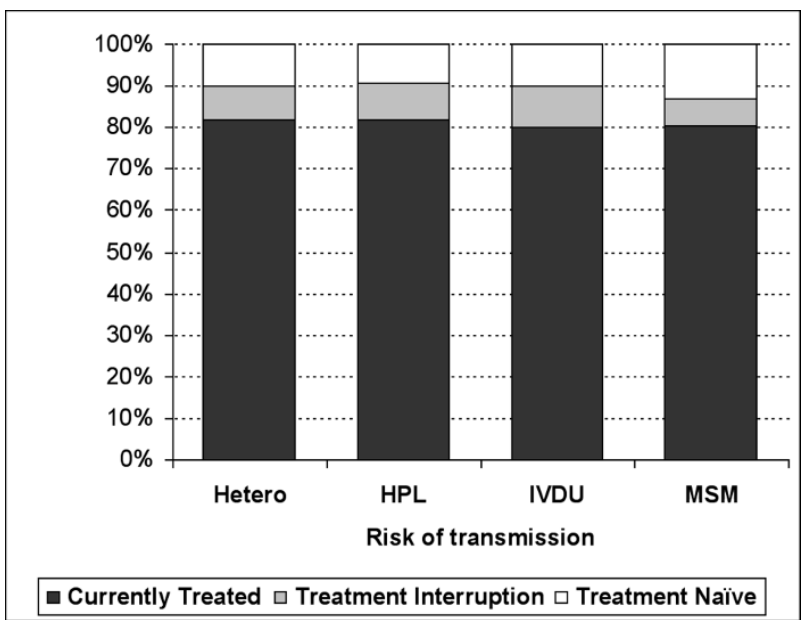

Fig. 7. Therapy status of patients under follow up at 20.10.2008, by risk of transmission $(\mathrm{N}=8,213)$.

There were no major differences regarding therapy status by risk of transmission, except a slightly higher proportion of therapy-naïve patients in MSM (Fig. 7).
The current number of assured documented initially treated patients was 3,265. The distribution of risk of transmission regarding treated patients with assured documented therapy-naivety equals the overall distribution of risk of transmission (Table 3). The mean duration between first positive HIV-diagnosis and start of initial ART fluctuated between 2.5 years and 5.3 years with a distinct increase in 2007 (Fig. 8). There were no significant differences regarding the this duration between men (3.3 years, IQR: 0.2-4.7) and women (3.7 years, IQR: $0.2-5.6, \mathrm{p}=0.06)$. The mean age at start of initial therapy differed between men (40, IQR: 33-46) and women (36, IQR: 29-41), p<0.001).

The mean CD 4 cell count $/ \mu \mathrm{l}$ at date of first documentation fluctuated between 275 and 448 and increased over time (Fig. 9). HPL had the lowest mean CD 4 cell count/ $\mu \mathrm{l}$ at date of first documentation (298, Table 3), MSM the highest (387). The mean CD4 cell count $/ \mu$ l of currently treated patients differed not significantly between men (538, IQR: 348-683) and women (518, IQR: 334-669, $\mathrm{p}=0.06$ ) It varied between 217 in 1995 and 548 in 2008, and increased since 1996 (Fig. 10). Regarding risk of transmission, IVDU had the lowest mean CD 4 cell count/ $\mu$ l of currently treated patients (480, Table 3), MSM the highest
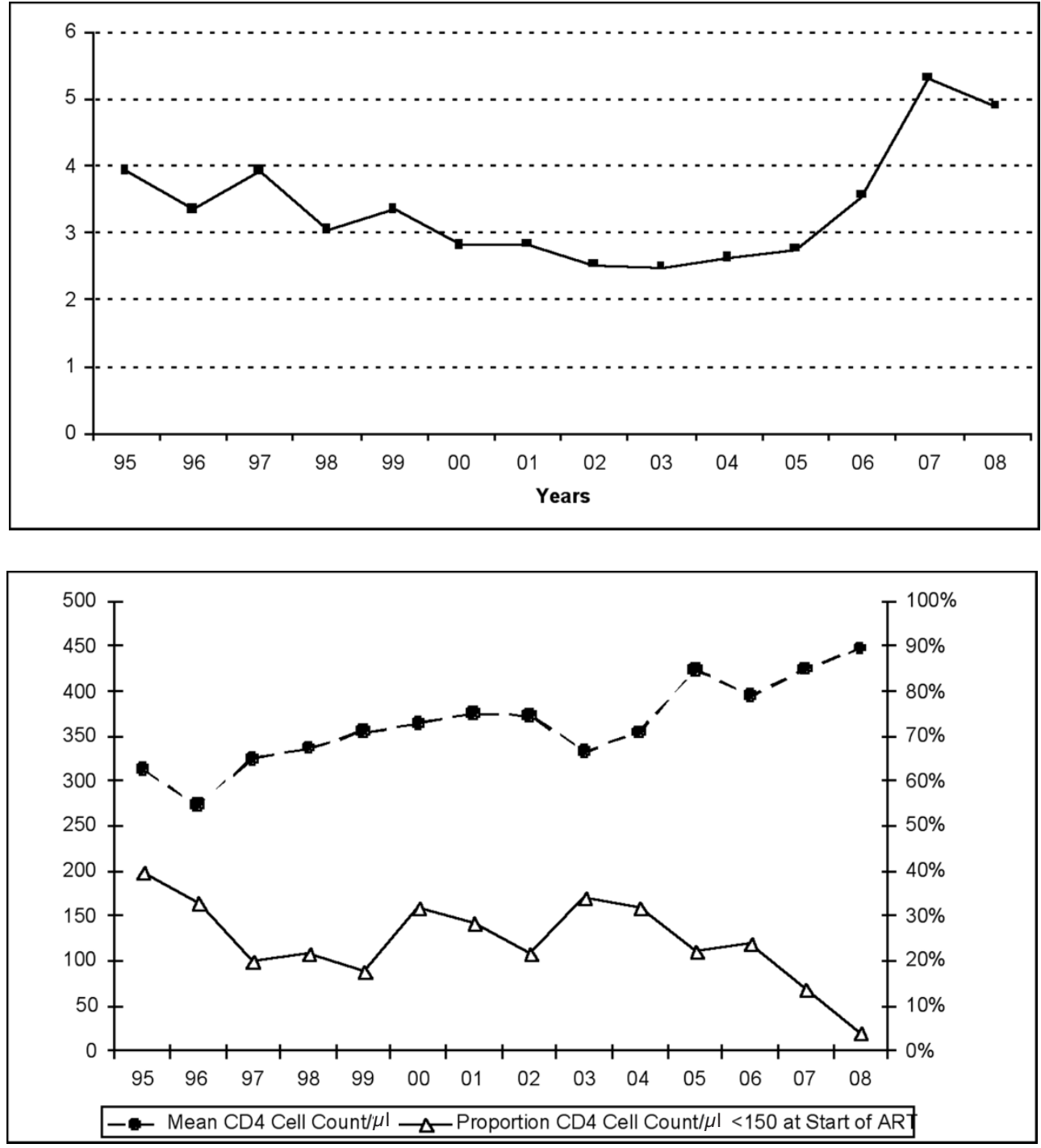

Fig. 8. Mean duration between first positive HIVtest and start of initial ART, including retrospective data, 1995-2008, by year $(\mathrm{N}=3,265)$.
Fig. 9. Mean CD4-cell count $/ \mu$ at date of first documentation and proportion of patients having CD4 cell count $/ \mu l<150$ at start of initial therapy, including retrospective data, 1995-2008, by year $\left(\mathrm{N}_{\mathrm{CD} 4 \text { cell count } / \mu \mathrm{l}}=4,937\right.$; $\mathrm{N}_{\text {Proportion CD4 cell count } / \mu \mathrm{l}<150}$ $=2,082$ ). 


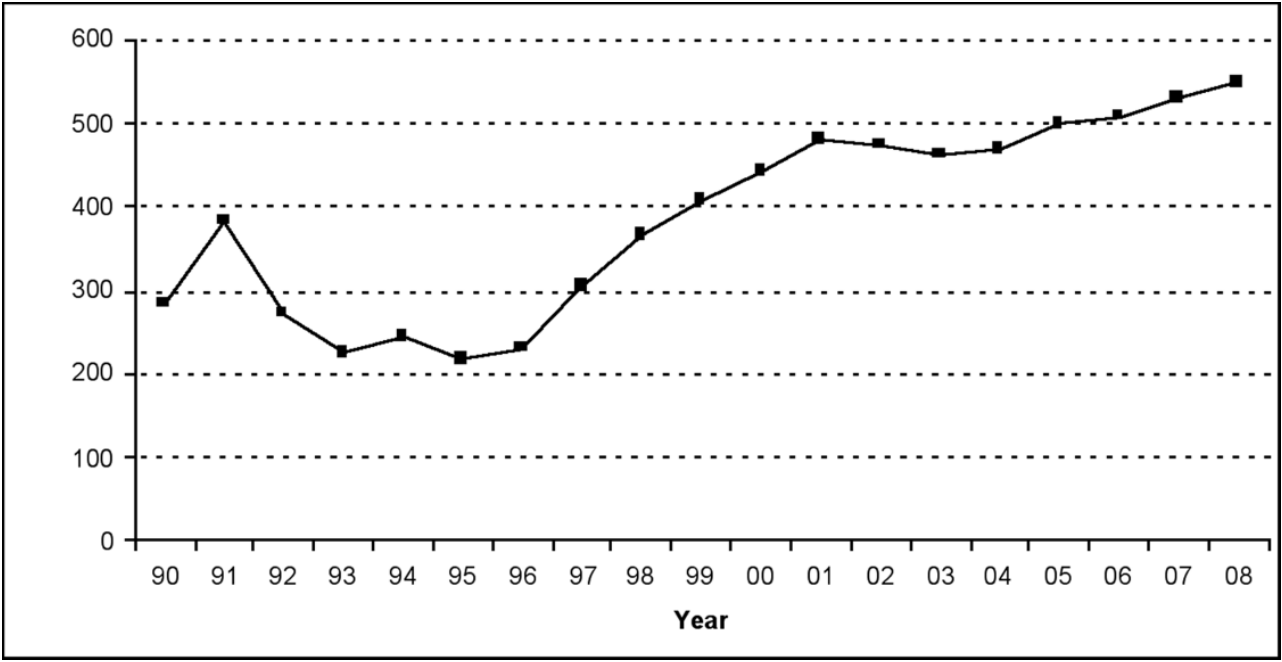

Fig. 10. Mean CD4 cell count $/ \mu$ of treated $\mathrm{pa}$ tients, including retrospective data, 1990-2008, by year $(\mathrm{N}=6,655)$.

Table 4. Distribution of ART-regimens with frequency $\geq 1 \%$ of patients being under treatment (not naive, no treatment interruption) and under follow up at 20.10.2008, frequency of prescribed substance classes, proportion of class-saving regimens, proportion of viral load below detection limit of regimens and classes $(N=6,655)$.

\section{Proportion (\%) VL $<$ detection limit $(\%)$}

\begin{tabular}{lcc}
\hline Regimen & & \\
2 NRTI + 1 PI + rtv & 35.5 & 76.1 \\
2 NRTI + 1 NNRTI & 35.9 & 88.0 \\
3 NRTI & 5.2 & 77.7 \\
3 NRTI + 1 PI + rtv & 4.7 & 69.7 \\
2 PI + rtv & 2.6 & 67.9 \\
4 NRTI & 1.7 & 60.3 \\
3 NRTI + 1 NNRTI & 1.7 & 85.8 \\
2 NRTI + 1 NNRTI + 1 PI +rtv & 1.0 & 79.4 \\
2 NRTI + 2 PI + rtv & 1.0 & 65.6 \\
1 NRTI+ 1 PI + rtv & 1.0 & 78.1 \\
1 PI + rtv & 1.0 & 64.2 \\
other & 8.7 & ---
\end{tabular}

\section{Substance classes}

$\begin{array}{lcc}\text { NRTI } & 90.7 & 79.6 \\ \text { NNRTI } & 39.5 & 87.4 \\ \text { PI } & 50.4 & 74.1 \\ \text { Fusion-Inhibitors } & 1.2 & 62.7 \\ \text { Entry-Inhibitors } & 0.5 & 50.0 \\ \text { Integrase-Inhibitors } & 1.7 & 54.5 \\ \text { Maturation-Inhibitors } & --- & ---\end{array}$

\begin{tabular}{lcc}
\hline Class-saving regimen & & \\
total & 10.6 & 70.5 \\
solely NRTI & 7.4 & 71.3 \\
solely PI & 3.2 & 68.6 \\
\hline
\end{tabular}

(553). The proportion of patients having viral load $<$ detection limit in currently treated patients differed not significantly between sexes (men: $78.6 \%$, women: $76.3 \%, p=0.1$ ).

Of about two third of all patients being assured documented as initially treated, data on CD4 cell count $/ \mu \mathrm{l}(63.2 \%)$ and viral load $(59.2 \%)$ at initial therapy were documented. The mean CD4 cell count/ $\mu$ at start of initial ART differed not significantly between men (292, IQR: 159-389) and women (315, IQR: 155423, $\mathrm{p}=0.06$ ) and fluctuated over the years (Fig. 11). After a rather low level between 2003 and 2006, it increased distinctly. There were no major differences between risks of transmission, excepting patients originating from HPL having a lower mean (Table 3 ). The mean of HIV RNA log copies/ml stayed stable between about 4 and $4.5 \log$ copies over time (Fig. 11) and differed slightly between the sexes(men: 4.2, IQR: 


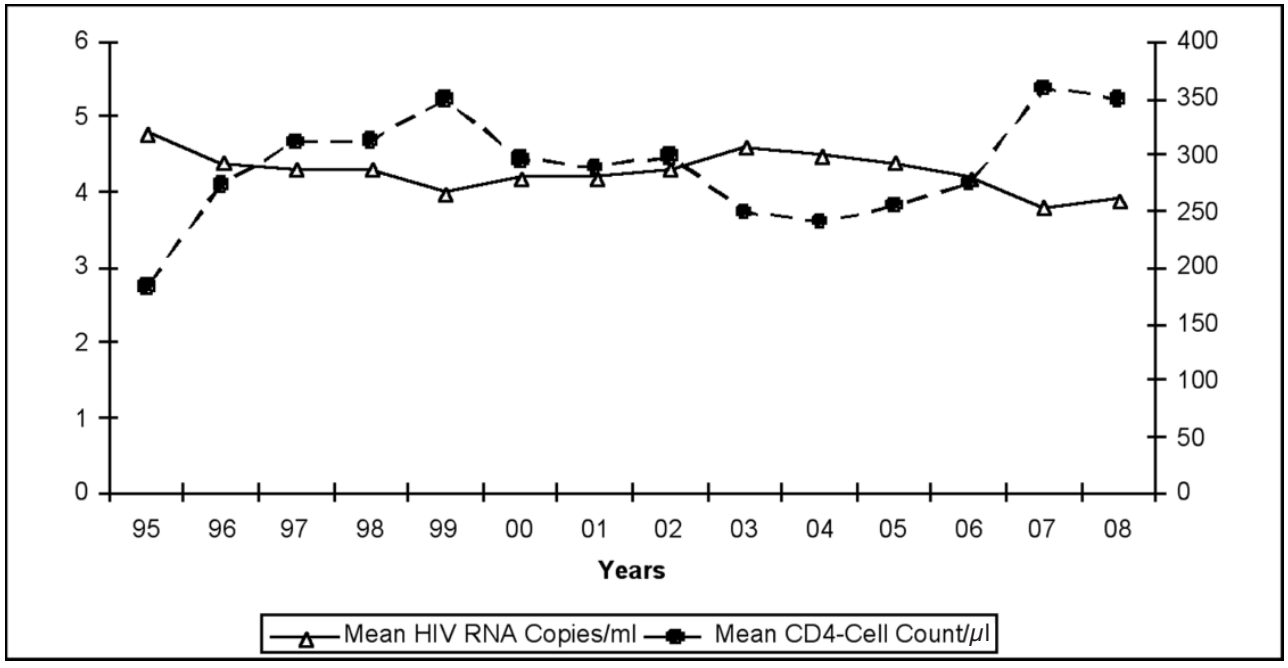

Fig. 11. Mean HIV RNA $\log$ copies $/ \mathrm{ml}$ and mean CD4 cell count/ $\mu$ at start of initial therapy, including retrospective data, 1995-2008, by year $\left(\mathrm{N}_{\text {HIV RNA Copies }}=1,933\right.$; $\left.\mathrm{N}_{\mathrm{CD} 4 \text { cell count } / \mu \mathrm{l}}=2,063\right)$.

3.4-5.2; women: 3.9, IQR: 3.0-4.9; $\mathrm{p}=0.001) .{ }^{4}$ Also regarding the risk of transmission, there were no considerable differences (Table 3). The proportion of patients having CD4 cell count $/ \mu \mathrm{l}<150$ at start of initial ART varied mainly between $20 \%$ and $30 \%$ over time (Fig. 9). This applied also to the distribution regarding risks of transmission, with the highest proportion in patients originating from HPL (Table 3).

The distribution of cART of currently treated patients showed two main regimens: 2NRTI/1PI+rtv and 2NRTI/1NNRTI (Table 4). The population being treated with 2NRTI/1NNRTI had the highest proportion of patients with viral load below detection limi $(88.0 \%)$.

NRTI were used in $90.7 \%$ of all regimen; fusion inhibitors, entry-inhibitors, Integrase-inhibitors and maturation inhibitors were used seldom (Table 4). About ten percent of class-saving regimen were prescribed currently, dominated by NRTI (Table 4).

\section{Discussion}

Currently, the KompNet cohort covered about a quarter of all treated HIV-positive patients in Germany, which were estimated as about 30,000 in 2008 [4]. Regarding the geographical distribution and the specialities of the documenting sites, central epidemiological and clinical characteristics of its patients, and considering the special characteristics of a cohort recruiting patients via treating institutions, the KompNet cohort is quite representative for the German epidemiological and treatment situation [1].

The lower number of newly recruited patients in 2007 and 2008 were due to a temporarily lowered recruitment following a cohort size reduction in 2007 [1]. It caused a decrease of patients followed up in 2007 and 2008. The cohort recruits new patients to picture current trends of epidemiology and treatment in Germany. Starting 2009, patients are recruited, presenting treatment-naïve at the sites since 2008, to be able to picture recent initial therapy regimen.

${ }^{4}$ Viral loads of patients below detection limit were calculated as detection limit-1, depending on the specific test.
The death- and lost to follow up-rates of the KompNet cohort were considerably below rates of other comparable cohorts $[5,6,7,8,9]$, because most patients were recruited not until 2005/2006. Over time, we expect an increase of these rates. Their drop in 2008 is because only $56.3 \%$ of all patients had already a complete documented follow-up for 2008 at state of date.

The mean duration between the first positive HIVtest and enrolment into the cohort decreased over time. Therewith, the overall population encloses more patients having shorter durations of infection, an important condition to picture recent, especially initial, treatment strategies.

The sex distribution stayed stable over time, regarding the prospectively and retrospectively documented population. It represented the epidemiological situation in Germany well $[1,3]$. This applied also to the distribution of risk of transmission with MSM as most frequent risk by far, the declining proportion of IVDU and the growing proportion of patients originating from HPL $[1,3]$. The latter was reflected by a growing proportion of patients with nationality of Subsaharan countries. Nevertheless, due to a partly high threshold for access and difficulties in recruiting migrants not originating from Western countries for a surveillance system like a cohort, the proportion of migrants and patients coming from high prevalence countries in the KompNet cohort is only half of the proportion of the data on newly diagnosed infections, for both sexes $[1,10,11]$

The changes of age distribution towards higher age groups over time were due to the retrospective documentation of the population that was recruited since 2004 and reflected similar changes in the epidemiological situation in Germany $[1,3]$. With a mean age of more than 40 years at enrolment and currently about $60 \%$ of patients between 30 to 50 years of age, the population of the KompNet cohort reflects the epidemiological situation in Germany as well [1]. The vocational situation is characterised by high proportions of unemployed persons, especially in women. There were significant correlations between stage of disease and income situation within the cohort [12].

The proportions of cohort patients being treated in clinics and by private practitioners were similar to the 
situation of treatment and care regarding HIV/AIDS in Germany [1]. There were differences regarding sociodemographic and clinical characteristics of the patient populations of both types, but only minor disparities regarding central clinical outcomes [13]. The high proportion of patients classified as CDC-stage B within the population is coherent for a cohort that recruits patients by treating institutions [1]. The high proportion of HPL classified as CDC-stage A was remarkable and will be analysed further. The proportions of Hepatitis B and C-confections within the several groups at risk reflected general epidemiological trends in that groups of HIV-positive patients [14, 15, $16,17]$. The high proportion of Hepatitis C-coinfections in patients infected by heterosexual contacts is assumed to often unreported risk of IVDU in that subpopulation.

Retrospectively documented data on central clinical parameters (CDC-stage, CD-4 cell count/ $\mu$ l, viral load) are under constant completion by the documenting sites. Of about two third of all patients being assured documented as initially treated, data on CD4 cell count $/ \mathrm{ml}$ and viral load at the time point of the initial therapy was documented. Due to missing values regarding early years of documentation, the figures on CDC-stage, CD-4 cell count/ $\mu$, and viral load concerning initially treated patients pictured the timeframe between 1995-2008 to ensure meaningful numbers.

The proportion of patients under treatment within the cohort increased heavily over time, especially in the consequence of introduction of cART (combined antiretroviral therapy) in Germany in 1996. The distinct increase of the mean CD 4 cell count/ $\mu$ l of currently treated patients between 1996 and 2001 pictures the introduction of cART and the improvement of its clinical effectivity. In the following, the curve remained mainly stable with an only light increase. The lower mean CD4 cell count/ $\mu$ l of currently treated patients in patients originating from HPL and IVDU probably reflects impairments as to access to treatment respectively as to compliance in these populations $[10,11]$.

The increase of the mean CD 4 cell count/ $\mu$ lat first documentation at the documenting site can be interpreted as a hint for an earlier presentation of the patients at the documenting site. Following that reasoning, patients originating from HPL having the lowest mean presented later; MSM and IVDU, both with distinct higher means presented earlier at the documenting site. Detailed analyses of late presenters within the KompNet cohort endorsed this assumption [18]. Regarding IVDU being in clinical care, the often frequent clinical monitoring and testing for HIV can assumed as reason for that; as to MSM, there is evidence for a high knowledge on the risks of HIV infection and the importance of regular HIV-testing in Germany [19].

Further, the increase of the mean CD4 cell count/ $\mu$ at first documentation at the documenting site corresponded to the increase of the mean duration between the first positive HIV-diagnosis and the start of the initial ART: with higher CD4 cell count $/ \mu \mathrm{l}$, ART can be initiated later. This applied also to the higher mean CD4 cell count/ $\mu$ at date of first documentation in MSM and the higher proportion of treatment-naïve patients in this group.

The increase of the mean CD 4 cell count/ $\mu$ l at start of the initial ART after 2006 indicates a tendency towards an earlier start of ART since that time point. The low mean in patients originating from HPL and their high proportion in patients having a CD4 cell count $/ \mu \mathrm{l}<150$ at start of the initial ART did not equal their distribution regarding CDC-stages. This has to be investigated further. The proportion of patients having CD4 cell count/ $\mu$ l below 150, varying mainly between $20 \%$ and $30 \%$ over time, was high and did not comply with current national and international treatment guidelines [20, 21, 22].

According to these guidelines, there were two main treatment regimens documented for currently treated patients: two NRTI as backbone combined with one NNRTI or one boostered PI, covering more than $70 \%$ of all regimens. NRTI as backbone were used in nearly all therapies, PI in half of all cases. The new substance classes fusion inhibitors, entry-inhibitors, Integrase-inhibitors and maturation inhibitors were reported only seldom, most frequent Integrase-inhabitors. Ten percent of all currently treated patients received class-saving regimens, dominated by NRTI. Overall, the proportion of patients having a viral load below detection limit were highest in patients being treated with NNRTI, though not corrected for influencing factors like number of regimens before, sex, CDC-stage etc. In Germany, patients having a more progredient HIV-infection are more likely to be treated with PI-based regimens, so this might be an important influencing factor $[20]$.

In summary, the KompNet cohort is an extensive instrument to measure the epidemiology of patients being in clinical care in Germany, the prescribing practices of ART and aspects of pharmacovigilance nationwide, imaging the German treatment specifics and their outcomes. The cohort includes many elder patients, which is important to analyse the special impact of ART and its side effects within a currently ageing HIV-population. It contains relevant numbers of women and migrants for analyses of subpopulations. Therewith, the KompNet cohort is of high impact as a complement of the German surveillance instruments regarding HIV/AIDS.

Acknowledgments: First, we thank all the patients participating in our cohort for providing their data and biomaterials to the cohort. We are grateful for all the work and dedication of the documentation officers and of the heads of our documenting sites. We thank the Ruhr-Universität Bochum for financial and structural encouragement. Especially, we thank the Federal Ministry of Education and Research for its ongoing financial and ideally support since 2002.

The following documenting sites contribute data to the basismodule of the KompNet cohort:

Gemeinschaftspraxis Driesener Straße, Berlin - Gemeinschaftspraxis Mehringdamm, Berlin • Gemeinschaftspraxis Turmstraße, Berlin - Gemeinschaftspraxis Fuggerstraße, Berlin - Praxiszentrum Kaiserdamm, Berlin - Universitätsklinikum Benjamin Franklin, Charité, Berlin • Dermatologische Klinik, Ruhr-Universität, Bochum • Universitätsklinikum 
Dortmund - Universitätsklinikum, Düsseldorf $\bullet$ Medizinische Klinik 3, Universitätsklinikum, Erlangen • Klinik für Dermatologie, Universität Essen - HIVCENTER, Universitätsklinikum, Frankfurt - Ifi-Institut, Hamburg - ICH Grindelpraxis, Infektionsepidemiologisches Centrum, Hamburg • Medizinische Hochschule, Hannover - Praxis Georgstraße, Hannover - Gemeinschaftspraxis, Kriegsstraße, Karlsruhe • Städtisches Krankenhaus Kemperhof, Koblenz • Praxis Hohenstaufenring, Köln • Gemeinschaftspraxis Isartorplatz, München $•$ MVZ Karlsplatz, HIV Research and Clinical Centre , München - Praxisgemeinschaft Franz Joseph-Straße, München • Klinikum, Osnabrück • Gemeinschaftspaxis Ulmer/Frietsch/Müller, Stuttgart

\section{REFERENCES}

1. Jansen K, Michalik C, Hahn, et al., and the Competence Network for HIV/AIDS. The Patient Cohort of the German Competence Network for HIV/AIDS (KompNet): A Profile. Eur J Med Res. 2009 August 12; 14(8): 323331.

2. Robert Koch-Institut. HIV/AIDS in Deutschland - Eckdaten. 2009.

3. Robert Koch-Institut. HIV-Infektionen/AIDS: Jahresbericht 2008. Epi Bull. 2009; 21.

4. Robert Koch-Institut. Changing epidemiology and consequences for prevention. Invited lecture at the SOEDAK 2009, St Gallen.

5. Jaggy C, von Overbeck J, Ledergerber B, Schwarz C, Egger M, Rickenbach M et al. Mortality in the Swiss HIV Cohort Study (SHCS) and the Swiss general population. Lancet 2003;362(9387):877-8.

6. Lloyd-Smith E, Brodkin E, Wood E, Kerr T, Tyndall MW, Montaner JSG et al. Impact of HAART and injection drug use on life expectancy of two HIV-positive cohorts in British Columbia. AIDS 2006;20(3):445-50.

7. Swiss Cohort Study. Probability of dying and dropping out in the SHCS, 1991-2008.

www.shcs.ch/html/figures/shcs_fig8.htm.

[Accessed: 23rd July 2009].

8. Lohse N, Hansen AB, Gerstoft J, Obel N. Improved survival in HIV-infected persons: consequences and perspectives. J Antimicrob Chemother 2007;60:461-63.

9. Phillips AN, Gazzard B, Gilson R, et al. Rate of AIDS diseases or death in HIV-infected antiretroviral therapynaïve individuals with high CD4 count. AIDS 2007 Aug 20;21(13):1717-21.

10. Steffan E, Kerschl V, Sokolowski S: Immigration and HIV/AIDS prevention in Germany - an interdisciplinary challenge. Euro Surveill. 2005; 10(1): E050120 4.

11. Robert Koch-Institut. HIV-Infektionen/AIDS-Erkrankungen: Halbjahresbericht I/2007. Epi Bull. 2007; $\mathrm{B} / 2007$.

12. Jansen $\mathrm{K}$, Brockmeyer $\mathrm{NH}$, Dlugay $\mathrm{V}$, et al., and the Competence Network for HIV/AIDS. Clinical outcomes of HIV-positive patients (PLWHA) having different income status: Results of an analysis on basis of the KompNet cohort. Eur J Med Res. 2009; Jun 24; 14 (Supl I): 9.
13. Jansen K, Brockmeyer NH, Haastert B, et al., and the Competence Network for HIV/AIDS. Do patients treated by outpatient clinics or by private practitioners face differing treatment characteristics and clinical outcomes in Germany? Eur J Med Res. 2009; Jun 24; 14 (Supl I): 104.

14. Robert Koch-Institut. Zur Situation bei wichtigen Infektionskrankheiten in Deutschland. Virushepatitis B, C und D im Jahr 2008. Epi Bull. 2009; 20.

15. Breijt N, Gilleece Y, Fisher M: Acute hepatitis C: changing epidemiology and association with HIV infection. J HIV Ther. 2007; 12(1): 3-6.

16. Schmidt AJ, Vogel M, Rockstroh JK, Radun D: Risk Factors for Hepatitis C in HIV positive MSM. A preliminary evaluation of a case control study. Poster for the 4th IAS Conference on HIV Pathogenesis, Treatment and Prevention, Sydney 2007.

17. Rantala M, van de Laar MJ: Surveillance and epidemiology of hepatitis B and C in Europe - A review. Euro Surveill. 2008; 13 (21).

18. Marcus U. Michalik C, Brockmeyer N, et al. Late and Early Presenters in the German KompNet Cohort - a comparison of sociodemographic variables. Eur J Med Res.2009, Jun 24; 14 (Supl I): 17.

19. Marcus U, Schmidt AJ. What do men who have sex with men in Germany know about the most common sexually transmitted infections? Eur J Med Res.2009, Jun 24; 14 (Supl I): 16.

20. Antiretroviral therapy of HIV infection. German-Austrian guidelines (position in September 2008). Dtsch Med Wochenschr; 2009 Jan;134 Suppl 1:4-15.

21. Clumeck N, Pozniak A, Raffi F. European AIDS Clinical Society (EACS) guidelines for the clinical management and treatment of HIV-infected adults. HIV Medicine 2008;9(2):65-71.

22. Panel on Antiretroviral Guidelines for Adults and Adolescents. Guidelines for the use of antiretroviral agents in HIV-1-infected adults and adolescents. Department of Health and Human Services. November 3, 2008; 1-139.

Address for correspondence:

Dipl.-Psych. Klaus Jansen

Competence Network for HIV/AIDS

Clinic for Dermatology and Allergology

Ruhr-Universität Bochum

Gudrunstr. 56

44791 Bochum

Germany

Fon: +49-234-509 3501

Fax: $\quad+49-234-5093475$

E-mail: klaus.jansen@klinikum-bochum.de 